\title{
Fuel Production for LWRs - MOX Fuel Aspects
}

\author{
Paul Deramaix
}

\begin{abstract}
Plutonium recycling in Light Water Reactors is today an industrial reality. It is recycled in the form of $(\mathrm{U}, \mathrm{Pu}) \mathrm{O}_{2}$ fuel pellets (MOX), fabricated to a large extent according to $\mathrm{UO}_{2}$ technology and pellet design. The similarity of physical, chemical, and neutron properties of both fuels also allows MOX fuel to be burnt in nuclear plants originally designed to burn $\mathrm{UO}_{2}$. The industrial processes presently in use or planned are all based on a mechanical blending of $\mathrm{UO}_{2}$ and $\mathrm{PuO}_{2}$ powders. To obtain finely dispersed plutonium and to prevent high local concentration of plutonium, the feed materials are micronised. In the BNFL process, the whole $\left(\mathrm{UO}_{2}, \mathrm{PuO}_{2}\right)$ blend is micronised by attrition milling. According to the MIMAS process, developed by BELGONUCLEAIRE, a primary blend made of $\mathrm{UO}_{2}$ containing about $30 \% \mathrm{PuO}_{2}$ is micronised in a ball mill, afterwards this primary blend is mechanically diluted in $\mathrm{UO}_{2}$ to obtain the specified Pu content. After mixing, the $(\mathrm{U}, \mathrm{Pu}) \mathrm{O}_{2}$ powder is pressed and the pellets are sintered. The sintering cover gas contains moisture and $5 \mathrm{v} / \mathrm{o} \mathrm{H}_{2}$. Moisture increases the sintering process and the U-Pu interdiffusion. After sintering and grinding, the pellets are submitted to severe controls to verify conformity with customer specifications (fissile content, Pu distribution, surface condition, chemical purity, density, microstructure).
\end{abstract}

Keywords: MIMAS · MOX · Plutonium · Quality

\section{Introduction}

Plutonium recycling in Light Water Reactors is today an industrial reality. This success comes from the large quantities of plutonium available from spent $\mathrm{UO}_{2}$ fuel reprocessing. The high energetic value of plutonium is transformed into heat to produce electricity by means of nuclear reactors initially designed to burn $\mathrm{UO}_{2}$, and modified to burn MOX $\left((\mathrm{U}, \mathrm{Pu}) \mathrm{O}_{2}\right)$ fuel. The hardware modifications are generally minor owing to the similarity of thermalmechanical and neutron properties of $\mathrm{UO}_{2}$ and MOX fuels.

The fabrication of MOX fuel pellets is based on the technology developed for the

${ }^{*}$ Correspondence: P. Deramaix

BELGONUCLEAIRE

4 avenue Ariane

B-1200 Bruxelles, Belgium

Tel.: +32 27740511

Fax: +32 27740610

E-Mail: p.deramaix@belgonucleaire.be
$\mathrm{UO}_{2}$, i.e. oxide powder conditioning, mixing of $\mathrm{UO}_{2}$ and $\mathrm{PuO}_{2}$ powders, pelletising, sintering, and grinding. However, numerous specificities of $\mathrm{PuO}_{2}$ (radioactivity, $\mathrm{Pu}$ isotopic composition, $\mathrm{PuO}_{2}$ chemical and physical properties, $\mathrm{Pu}$ content and final homogeneity) require a dedicated fabrication process.

This paper presents a global overview regarding MOX manufacturing plant history and the situation today, followed by a description of the MIMAS MOX fabrication process, and the specific solutions found to cope with quality requirements.

\section{Fabrication Capacities [1][2]}

Significant MOX fuel fabrication activities have been conducted since the 1950s in Belgium and in the USA, since the 1960s in France, Germany, Japan, the Russian Federation and the UK, and since the 1970s in India.

In the USA, five pilot facilities with a combined fabrication capacity of 50-70 tHM/year (tons of heavy metal per year) were in operation up to 1976 when President Carter took the political decision to defer reprocessing indefinitely, which resulted in shutdown and decommissioning of those five facilities.
In Germany, the SIEMENS/Hanau plant, which started operation in 1972 as a dual purpose (FBR and LWR) facility, reached an effective capacity of 20-25 tHM/year of LWR fuel in the 1987-1991 period. It was shutdown by order of the Hessen Ministry of Environment on the pretext of a contamination incident in June 1991 and since then decommissioned.

In Belgium, the BELGONUCLEAIRE plant started operation in 1973 on the basis of R\&D conducted since the 1950s in successive facilities from laboratory to pilot scale. During the first ten years of operation, the plant was equipped to fabricate both light water reactor (LWR)- and fast breeder reactor (FBR) fuel. On the basis of lessons learned during that period, the plant was refurbished in 1984-1985 to implement the current MIMAS process and to upgrade the nominal capacity up to 35 tHM/year for LWR fuel, the only fuel to be manufactured there after. Up to the beginning of 1987, the end products were LWR and FBR fuel assemblies. Thereafter, the end product has been fuel rods, with the assembling operation being performed in the adjacent Franco-Belge Fabrication de Combustible (FBFC) International (Dessel) uranium fuel manufacturing plant.

In France, the Cogema/Cadarache plant, initially (since 1962) devoted to FBR fuels, was partly adapted in the mid-1980s to 
manufacture MOX fuel for LWRs according to a home-developed process (COCA). Because of the high performance of the BELGONUCLEAIRE MIMAS process, this process was implemented in 1995 with a resulting capacity of up to $40 \mathrm{tHM} /$ year for LWRs up to mid-2003 when the plant was shutdown with the transfer of its capacity to the MELOX plant. This later plant, which started its operation in 1995, adopted from the beginning the BELGONUCLEAIRE MIMAS process. Its capacity was $100 \mathrm{tHM}$ /year of LWR fuel up to mid-2003 when it was upgraded to $145 \mathrm{tHM} /$ year to compensate for the shutdown of the $\mathrm{Ca}$ darache plant.

In the UK, in the early 1990s, BNFL equipped the MOX Demonstration Facility (MDF) at Sellafield to produce some MOX fuel for LWRs according to a home-developed process, the Short Binderless Route (SBR) to gain commercial experience on the production of MOX fuel in preparation for the large-scale Sellafield MOX Plant (SMP) under construction. MDF operated up to September 1999 when it was shutdown due to quality-related issues. SMP, an automated plant with a nominal 120 tHM/ year capacity, started its commissioning process with plutonium in 2001. However since then, by May 2005, due to the difficulties to set up the process parameters, it has produced barely more than $1 \mathrm{tHM}$.

The capacities of the facilities in operation in other countries (in Japan since 1972, in the Russian Federation since 1981, in India since 1994) are rather small. As a result:

- During the last five years, $99 \%$ of the manufactured MOX fuel was made according to the MIMAS process originally developed in the BELGONUCLEAIRE plant.

- By the end of 2004, a total of more than 1750 tHM of MOX fuel have contributed to the production of electricity in power LWRs in France, Germany, Belgium, Switzerland: $88 \%$ of this MOX fuel was produced according to the MIMAS process.

- The US DOE decided in 1999 to build a MOX fabrication plant in the USA to process 34 tHM of weapon-grade plutonium into MOX fuel for use in some US PWRs. The MIMAS process was selected as the reference process for that plant. The same process is therefore the main candidate process for a similar plant in the Russian Federation for the same purpose.

- Similarly, the Japanese Utilities decided to select the MIMAS process as the reference process for a MOX plant to start operation in Japan from about 2012.

The outline of the MOX fabrication technology as presented here is therefore based on the MIMAS process.

\section{Mimas MOX Fabrication Technology}

In $\mathrm{UO}_{2}$ fuel, the fissile material is inherently present in the fuel. In the MOX fuel, the fissile material, namely the plutonium, has to be added to the uranium support. This blending of the two materials is the most specific difference between $\mathrm{UO}_{2}$ and $\mathrm{MOX}$ fuel manufacturing.

The MIMAS process, developed by BELGONUCLEAIRE in the early 1980s is an adaptation of the reference fabrication process developed earlier and applied commercially in the 1970s at the Dessel Plant. The reference process consisted of a single blending of $\mathrm{PuO}_{2}$ powder with free-flowing $\mathrm{UO}_{2}$ powder (namely ex AUC-UO $\mathrm{U}_{2}$ ), resulting in a blend of adequate flowability to feed the pellet press. The process parameters used for pressing and sintering were rather similar to those used for the fabrication of $\mathrm{UO}_{2}$ pellets using the same free-flowing $\mathrm{UO}_{2}$ powder and the characteristics of both types of pellets were very close in terms of density, resintering behaviour, pellet surface defects, hydrogen content, impurities content, and behaviour under irradiation. The main challenge was to obtain a $\mathrm{PuO}_{2}$ distribution sufficiently uniform in the finished pellets: the characteristics of the $\mathrm{PuO}_{2}$ as received from the reprocessing plants (obtained by calcination of plutonium oxalate) are such that the $\mathrm{PuO}_{2}$ powder presents some tendency to agglomerate somewhat in spite of a forced sieving of the $\mathrm{PuO}_{2}$ during the blending preparation and of an optimisation of the blending parameters. The presence of pure $\mathrm{PuO}_{2}$ particles exceeding a diameter of $550 \mu \mathrm{m}$ in the finished pellets might be detrimental to the integrity of the fuel rods in case of fast reactivity insertion (i.e. RIA) [3]. Specific control techniques were developed to evaluate the uniformity of the $\mathrm{PuO}_{2}$ distribution in the pellets, either destructively (by alpha-autoradiography, or electron probe microanalysis) or non destructively (by neutron radiography of finished rods). With the construction of the current reprocessing plants (La Hague, Sellafield), the MOX fuel manufactured according to the above-mentioned reference process was no longer acceptable, as it was not soluble enough in pure nitric acid solution in the conditions of those reprocessing plants, even after irradiation. The single blending step of the reference process was replaced by a two-step blending approach (Fig. 1): in the first step, the pure $\mathrm{PuO}_{2}$ fuel and some $\mathrm{UO}_{2}$ are co-micronised in a ballmill, resulting in a primary blend (master) of $\mathrm{UO}_{2}-\mathrm{PuO}_{2}$ containing at $\max 40 \% \mathrm{PuO}_{2}$ (MOX crystallographic lattices containing less than 40 to $50 \% \mathrm{Pu} / \mathrm{U}$ are indeed soluble in pure nitric acid). In the second step, the primary blend is blended down with freeflowing $\mathrm{UO}_{2}$ to the specified $\mathrm{Pu}$ content of the MOX fuel. The very close contact between the micronised $\mathrm{UO}_{2}$ and $\mathrm{PuO}_{2}$ particles enhances adequate interdiffusion during sintering which guarantees enough solubility as required by the reprocessors, and which in addition prevents the formation of pure $\mathrm{PuO}_{2}$ agglomerates in the finished pellets.

All the subsequent process steps after the preparation of the MOX powder are rather similar to those for $\mathrm{UO}_{2}$ fuel except for the environmental controls due to the radiotoxicity of the Pu bearing powders:

- Pressing is carried out in hydraulic presses.

- Sintering is conducted in continuous furnaces but with wet sintering gas containing max. 5 v/o of $\mathrm{H}_{2}$ to prevent any risk of explosion.

- Centerless grinding is performed in dry conditions.

- Tungsten inert gas welding (TIG) is used for both the circular top end plug welding and for the prepressurisation venthole sealing.

- All the above-mentioned operations are performed in glove boxes, under slight negative pressure. The filling and welding unit is designed with minimal penetration of the cladding into the glove box to minimise the finished fuel rod surface contamination, decontamination and contamination monitoring.

- The finished rods, after their controls, are positioned in magazines and drawn from the magazines through the fuel assembly skeletons.

\section{Main Problems Solved to Meet MOX Fuel Quality Requirements}

The quality requirements for MOX fuel are identical to those for $\mathrm{UO}_{2}$ fuel used in the same reactors

\subsection{Pellet Density - Microstucture and Pellet Surface Defects}

The results obtained for those characteristics are mainly governed by the ability to produce pellets of a mixture of free-flowing $\mathrm{UO}_{2}$ powder into which the micronised primary blend is blended. However the fine micronised (U-Pu) $\mathrm{O}_{2}$ powder of the primary blend surrounding the $\mathrm{UO}_{2}$ grains of the free-flowing $\mathrm{UO}_{2}$ alters somewhat the densification and the enlargement of the $\mathrm{UO}_{2}$ grain sizes, preventing the required pellet density, and a desirable microstructure (grain size and porosity distribution, with almost all pores closed) of finished pellets which would result in an adequate stability of the pellets during irradiation (resintering behaviour), and in a low residual hydrogen content in the fuel rods. The process parameters were optimised for that purpose, in particular: 


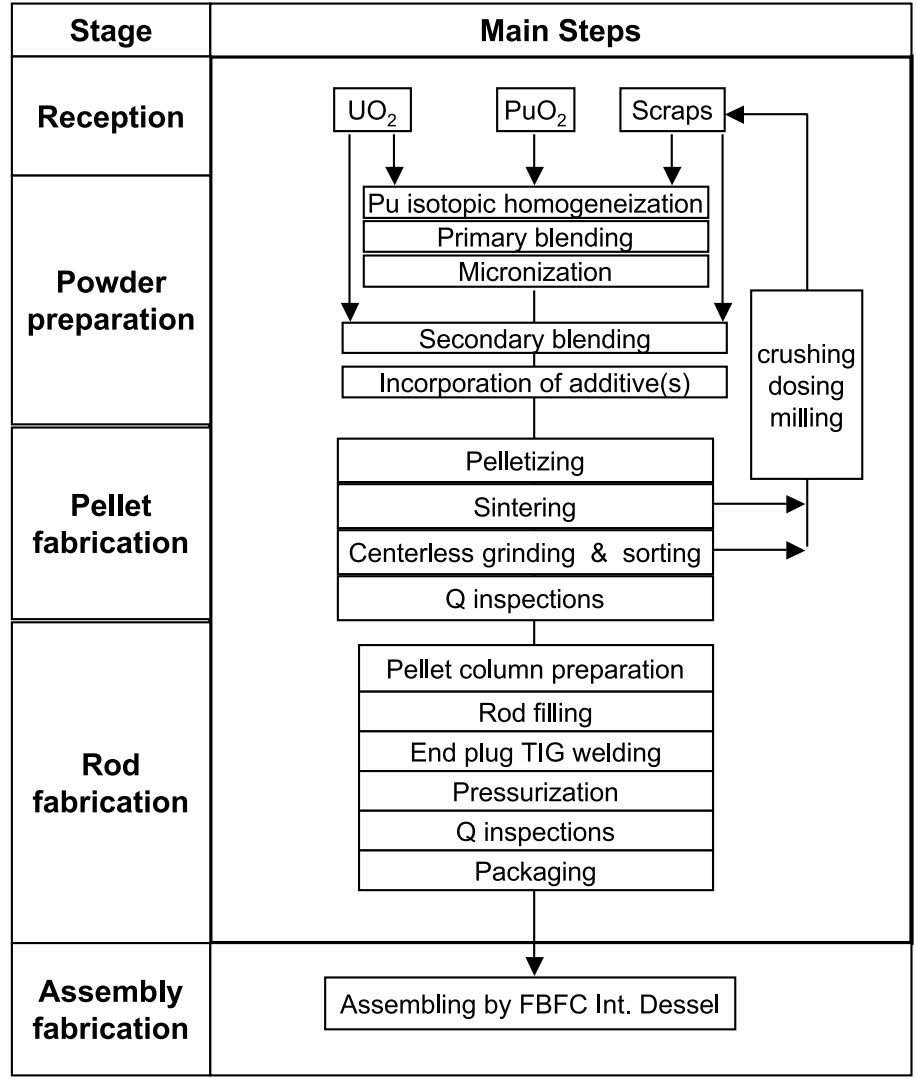

Fig. 1. Flowsheet of the MIMAS process

- At the level of the secondary blending: duration of the blending and rotation speed of the set of equipment;

- At the level of the in-furnace sintering: temperature profile and duration, injection of adequate quantity of steam in the sintering furnace to enhance further the densification process, the enlargement of the grain size, the interdiffusion of the micronised primary blend into the $\mathrm{UO}_{2}$ feed, and to avoid the closing of the pores at the end of the process, enabling all the volatile gas to escape from the pellet before.

\subsection{Homogeneity of the Plutonium Distribution within a Pellet}

A homogeneous distribution of the $\mathrm{PuO}_{2}$ inside the MOX pellet ensures solubility of the MOX fuel in pure nitric acid solution. It provides a resistance to cladding failure similar to that for $\mathrm{UO}_{2}$ fuel in the case of fast reactivity initiated accidents. It minimises fission gas release in normal fuel irradiation conditions.

The process parameters were optimised for that purpose, in particular:

- At the level of the primary blend preparation: duration of the micronisation and its homogenisation;

- At the level of the secondary blending: duration of the blending.

Optimisation of the sintering parameters, as explained under Section 4.1. results simultaneously in an improvement of the interdiffusion of the micronised powder of the primary blend into the $\mathrm{UO}_{2}$ matrix.

Based on the above-mentioned optimisations and routine alpha-autoradiographic inspection (Fig. 2), it could be proven that no more than $5 \%$ of the $\mathrm{Pu}$ content of the pellets is present in agglomerates with a diameter exceeding $30 \mu \mathrm{m}$, with no agglomerates with diameter exceeding the threshold of $550 \mu \mathrm{m}$.

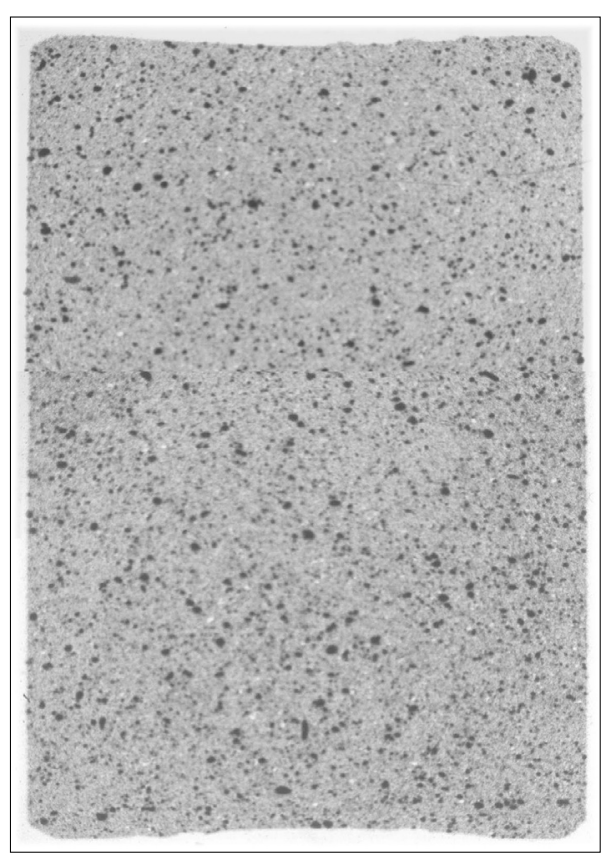

Fig. 2. $\alpha$-Autoradiography of MIMAS fuel

\subsection{Pellet to Pellet Plutonium Distribution}

Although the pellet to pellet enrichment of $\mathrm{U} 235$ in $\mathrm{U}$ is practically constant in the $\mathrm{UO}_{2}$ fuel, the $\mathrm{Pu}$ content can vary from pellet to pellet within the same fabrication batch as a result of the mechanical blending of the various constituents (primary blend, free-flowing $\mathrm{UO}_{2}$, recycled scraps) of the secondary blends.

The optimisation of the blending parameters (see Section 4.2.) and the optimisation of feeding the secondary blend powder into the dies of the hydraulic presses to minimise the segregation of the various constituents enable the production of MOX pellets with acceptable $\mathrm{Pu}$ concentration variation between pellets. The statistical combination factor of the power peak effects resulting from the pellet to pellet $\mathrm{Pu}$ content variation, from the pellet to pellet density variation and dimension differences (namely the engineering factor) is acceptable with regard to the same factor for $\mathrm{UO}_{2}$ fuel.

\subsection{Scrap Recycling}

Scraps are generated as powders by the process itself (dry centerless grinding fines), by the rejected products (non conforming pellets) and by the surpluses fabricated before switching to the next fabrication campaign.

The liquid materials generated are very limited: they consist of chemical solutions resulting from some inspections ( $\mathrm{Pu}$ content, isotopic composition, solubility). The liquids are treated afterwards to retrieve the $\mathrm{Pu}$ as $\mathrm{PuO}_{2}$ or as $(\mathrm{Pu}-\mathrm{U}) \mathrm{O}_{2}$ powders.

All these scrap powders are carefully sorted and micronised, if needed, with addition of fresh $\mathrm{UO}_{2}$ powder, and are afterwards used for the preparation of primary blends. MOX fuel can now be produced with up to $76 \%$ of the primary blend powder consisting of so-conditioned scraps.

Practically all the plutonium made available by the customers for MOX fabrication which is not included in the finished MOX fuel, can be recycled.

\subsection{Uniformity of the Plutonium Isotopic Composition}

$\mathrm{PuO}_{2}$ is normally produced by the reprocessors in batches of more $120 \mathrm{~kg} \mathrm{Pu}$, conditioned in cans of around $3 \mathrm{~kg}$ (Cogema) to $6 \mathrm{~kg}$ (BNFL) for delivery to the fabrication plant. Depending on the average $\mathrm{Pu}$ content of the MOX fuel, a fabrication campaign requires 3-10 batches of $\mathrm{PuO}_{2}$.

The variability of the $\mathrm{Pu}$ isotopic compositions amongst the various $\mathrm{PuO}_{2}$ batches made available for a fabrication campaign depends on the types (PWR, BWR) and burnup of the fuels that have been reprocessed.

Uniformity of the Pu isotopic composition is achieved by computerised selection 
of three to five cans to be incorporated in the ball mill to produce one $60 \mathrm{~kg}$ primary blend. The computer programme takes into account the actual characteristics of each $\mathrm{PuO}_{2}$ can provided at the reprocessing plant, of the $\mathrm{PuO}_{2}$ cans available in the fabrication plant buffer storage, and of the scraps cans conditioned as explained in Section 4.4 , for incorporation in the primary blend. Experience has confirmed that usually the $\mathrm{Pu}$ isotopic composition is uniform enough within all the primary blends needed for a fabrication campaign.

If such homogenisation is not sufficient at the level of the primary blends, the MIMAS process offers the possibility of an additional cross-blending by feeding all the secondary blends of the fabrication campaign with the cans containing the powder of the various primary blends predetermined for such fabrication campaign.

\subsection{Hydrogen Content}

The hydrogen content must be minimised in LWR fuel cladded with $\mathrm{Zr}$ type materials to avoid clad deterioration by local inside hydriding.

$\mathrm{UO}_{2}$ fuel manufactured with the same type of free-flowing $\mathrm{UO}_{2}$ powder used to have a rather high fraction of open porosity, which tends to hold ambient moisture, in particular when wet pellet grinding is used. $\mathrm{UO}_{2}$ pellets are normally submitted to a drying process just before loading into fuel rods and upper end plug welding and sealing.

In the MOX fuel fabrication, the presence of large specific $\mathrm{PuO}_{2}$ surfaces in the MOX pellets as a result of the micronisation of the primary blends would increase the tendency to retain ambient moisture or the moisture created at the beginning of the sin- tering process. For all these reasons, all the process steps are carried out under inert gas or under dry air atmosphere. A dry grinding process was adopted, avoiding not only the eventual absorption of water inside the pellets, but making it also easier to meet the constraints of safety-critical requirements and to manage the handling/recycling of the grinding fines (see Section 4.5.).

In addition, the sintering process parameters as explained in Section 4.1. have been optimised to have most of the pores closed only at the end of the sintering process, enabling all the volatile gas to escape from the body of the pellet before the closure. No drying of the MOX pellets is required any longer before loading the pellets in the rods and the upper end plug welding and sealing.

\section{Conclusions}

During the last five years, $99 \%$ of the manufactured MOX fuel has been made according to the MIMAS process originally developed in the BELGONUCLEAIRE plant. In the USA and in Japan, the MIMAS process was selected as the reference process for their future MOX plants.

The MIMAS process was improved based on the requirements of the current reprocessing plants (La Hague, Sellafield) to have a MOX fuel soluble enough in nitric acid solution under the conditions of those reprocessing plants. This is obtained by a two-step blending approach of the $\mathrm{UO}_{2}-$ and $\mathrm{PuO}_{2}$ feed materials: micronisation of a first blend made of $\mathrm{UO}_{2}$ containing no more than $40 \% \mathrm{PuO}_{2}$, followed by mechanical dilution of this blend into $\mathrm{UO}_{2}$ to obtain the required $\mathrm{Pu}$ content. The obtained pellet is characterised by a fine and homogeneous dispersion of $\mathrm{Pu}$ rich particles, with insignificant fractions of $\mathrm{Pu}$ locally reaching the $\mathrm{PuO}_{2}$ content of the first blend. This result is obtained owing to special attention and optimisation of the following parameters:

- Duration of micronisation and homogenisation of the primary blends and duration of blending of the secondary blends.

- Sieving of the Pu-rich feed materials before secondary blending.

- Feeding of the hydraulic press to minimise segregation.

- Controlling quality and amount of scraps recycled in primary and secondary blends.

- Controlling the chemical purity of fresh materials and the absence of chemical contaminations during pellet pressing. and handling.

- Keeping appropriate sintering temperature profile and cover gas composition to reach correct density, stoichiometry, chemical purity, and microstructure.

Received: July 18, 2005

[1] OECD Nuclear Energy Agency, 'Management of Separated Plutonium - The Technical Options', OECD NEA, Paris, 1997.

[2] International Atomic Energy Agency, Technical Reports Series No. 415, 'Status and Advances in MOX Fuel Technology', IAEA, Vienne, 2003.

[3] M.D. Freshley, 'Behaviour of Discrete Plutonium-Dioxide Particles in MixedOxide Fuel During Rapid Power Transients', Nuclear Technology 1972, 15(2), 239-248. 